\title{
DIE INVLOED VAN RELIGIEUSE EN KULTURELE VERSKEIDENHEID OP MORALITEIT IN DIE HUIDIGE SUID-AFRIKAANSE KONTEKS: 'N Uitdaging VIR CHRISTELIKE KERKE
}

Author:

Christie van Zyl ${ }^{1}$

\section{Affiliation:}

${ }^{1}$ Nederduits Gereformeerde Kerk, Bethal-Oos, SuidAfrika

Correspondence to: Christie van Zyl

email:

pastorie@telkomsa.net

Postal address:

Posbus 558, Bethal 2310, Suid-Afrika

\section{Keywords:}

invloed; kultuur; religie; verskeindenheid; morele oriëntasie

\section{Dates:}

Received: 09 June 2010 Accepted: 29 Oct. 2010

Published: 25 Nov. 2010

How to cite this article: Van Zyl, C., 2010, ‘Die invloed van religieuse en kulturele verskeidenheid op moraliteit in die huidige Suid-Afrikaanse konteks: 'n Uitdaging vir Christelike kerke', Verbum et Ecclesia31(1), Art. \#405, 8 pages. DOI: $10.4102 /$ ve.v31i1.405

\section{This article is available} at:

http://www.ve.org.za

\section{Note:}

Hierdie artikel is gebasseer op ' $\mathrm{n}$ PhD proefskrif, onder leiding van prof. Etienne de Villiers, verbonde aan die Department Dogmatiek en Christelike Etiek, Fakulteit Teologie, Universiteit van Pretoria.

(c) 2010. The Authors. Licensee: OpenJournals Publishing. This work is licensed under the Creative Commons Attribution License.

\section{ABSTRACT}

The influence of religious and cultural diversity on the moral orientation of the current South African society: A challenge for the church

This article takes into account the morality crisis in South Africa against the background of the rich diversity in the country. It deals with the question whether religious and cultural diversity in particular contributes to moral decay in the community. Different peoples do not only have different experiences of life, but also different value systems on account of their different backgrounds and belief systems. They are the products of diverse influences which bring about different identities and moral orientations. On the one hand this can lead to conflict in societies. On the other hand, diversity in terms of religion and culture enriches societies. Much depends on how these differences are managed. Identity and leadership be regarded as two of the most important elements in the makeup of a prosperous society, especially when it comes to the factor of morality. Diversity demonstrates a great deal of dynamics in itself. It progressively develops new forms as people live actively amidst new circumstances and relationships. As the church is a central player in the field of building moral values, the church has the obligation to re-organise itself in terms of traditional diversity as well as the current contemporary religious and cultural experience.

\section{INLEIDING}

Suid-Afrika beleef tans 'n moraliteitskrisis. Vanuit hulle werklikheidservarings behoort die meeste inwoners van die land bevestigend op dié drastiese stelling te reageer. Die buitengewone hoë voorkoms van misdaad en veral die gewelddadige aard daarvan bied 'n maatstaf waarvolgens mens 'n begrip kan kry van die omvang van die morele problematiek. Min mense het nog nie onder die een of ander vorm van misdadigheid deurgeloop nie. Dit wissel van moord tot motorkapings, van verkragting tot huisbraak, van bedrog tot gesinsgeweld en baie ander vorme van vergryp teen mense. (De Villiers 1999:15-38)

Dit is egter nie net strafregtelike oortredings wat kommer wek nie, maar ook 'n toenemende gees van eiegerigtigheid, onverdraagsaamheid, selfsugtigheid en materialisme. Korrupsie onder vooraanstaandes en hooggeplaaste amptenare skep 'n atmosfeer van bandeloosheid en vergryp. Die indruk word deur hulle geskep dat sodanige gedrag aanvaarbaar is en sommiges gaan so ver as om te beweer dat alles maar toelaatbaar is solank jy daarmee kan wegkom. (Rauch 2005:9)

Sensitiewe menslike eienskappe soos seksualiteit, menswaardigheid, goeie arbeids- en gesinsverhoudinge, opregtheid, eerlikheid, betroubaarheid en verantwoordelikheid word in baie gevalle misverstaan en selfs teengeveg. Die fokus op korttermynverhoudings bring volhoubare toewyding ten opsigte van mekaar en wedersydse integriteit in gedrang. Huwelike ly skade en gesinsverbrokkeling kom al hoe meer voor. Die gevolg daarvan is 'n ontwrigte samelewing sonder duidelike gedragskodes.

Algemeen aanvaarde morele norme word skaars. Die basis waarop moraliteit gebou word, is meervoudig en spel verskillende gedragpatrone uit wat op hulle beurt verskillend geïnterpreteer word en in baie gevalle nie as rigtinggewend aanvaar word nie. Die Suid-Afrikaanse samelewing was nog nooit en sal ook nooit homogeen van aard wees nie, veral nie in terme van moraliteit nie. Hierdie toedrag van sake bemoeilik morele eenstemmigheid.

\section{DIE SUID-AFRIKAANSE VERSKEIDENHEID IS KOMPLEKS VAN AARD}

\section{Religieuse verskeidenheid}

Moraliteit word tot ' $n$ groot mate religieus bedink. Of ' $n$ besondere godsdiens se waardestelsel vanuit 'n eksterne profetiese inspraak gerig word of deur innerlike spirituele belewenis, dit vorm steeds die onderbou van die morele gedrag van die meeste mense.

Geloofsoortuigings soos die Christendom, Judaïsme én Islam bely byvoorbeeld dat die mens 'n skepsel van God is en dat hy as sodanig en na sy besondere aard 'n denkende en verantwoordelike wese bedoel is om te wees. Die mens leef onder God se gesag en in gehoorsaamheid aan Hom.

By Hinduïsme is die leer van karma en dharma betekenisvol waar dit kom by die etiese aspek van menswees. Eersgenoemde plaas klem op die interafhanklikheid van alle dinge en laasgenoemde op die harmonieuse funksionering van alles. Dit verlang verantwoordelike optrede van almal ten einde die sinvolle en bevredigende voortbestaan van die werklikheid te verseker. 
Vir die Boeddhis bestaan etiek uit die fundamentele deugde van medelye, welwillendheid, blydskap en gelatenheid. Liefde soos ons dit ken word nie hoog aangeslaan nie, want dit bring komplekse verhoudings mee. Morele reiniging en verlossing kan net in jouself volvoer word. Meditasie is die weg tot selfontwikkeling en -realisering. Hoewel Boeddhisme in 'n groot mate op die innerlike self gerig is, streef dit die welwese van, en respek vir almal na. (Morgan \& Lawton 1996:82)

By die Afrika Tradisionele Godsdiens sowel as Afro-Christelike geloofsgroepe word die opperwese ook as skepper erken, maar die rol wat afgestorwe voorouers speel, is steeds van die grootste belang. Dit is veral op die etiek van die samelewing gerig. Gedrag word deur vrees vir vergelding bepaal terwyl norme gerelativeer word op grond van subjektiewe belewenisse wat as opdragte van afgestorwe voorouers geïnterpreteer word.

Talle geloofsgroepe, elkeen met sy eie perspektiewe op etiese aangeleenthede word in Suid-Afrika aangetref. Uiteraard bestaan daar raakvlakke wat opbouend op die breë samelewing inwerk, maar ook verdelende verskille. Enersyds is daar byvoorbeeld ' $n$ groot mate van eenstemmigheid oor menswaardigheid, maar andersyds beklee die vrou nie oral ' $n$ gelyke posisie naas die man nie. Die sekulêre staatsbestel en gepaardgaande godsdiensvryheid wat sedert 1994 bestaan, het bepaalde positiewe gevolge, maar skep terselfdertyd ruimte vir diverse menings waar dit by morele kwessies kom. Ons land gaan gevolglik mank aan duidelike religieus-etiese konsensus. Vir individue wat nie oor 'n goed gedefinieerde morele verwysingsraamwerk beskik nie, saai die meerstemmigheid wat religieuse verskeidenheid meebring, verwarring. Een van die negatiewe nagevolge van sodanige verwarring is ' $n$ morele vakuum waarbinne mense hulle mag bevind. Hulle weet eenvoudig nie wat die verskil tussen aanvaarbare en onaanvaarbare gedrag is nie.

Die aard en rol van godsdiens het ' $n$ fundamentele verandering ondergaan desnieteenstaande van watter geloofsoortuiging sprake is. Tradisionele morele koersaanduiders wat vanuit die religieuse omgewing uitgaan, word nie meer onbevraagtekend aanvaar nie. Selfs binne bepaalde geloofstradisies kom daar 'n groeiende verskeidenheid na vore. Gemeentes van bepaalde Christelike kerke is nie meer eenders wat hul aard en bediengspraktyk betref nie. Enkele dekades gelede was dit nog nie die geval nie. Aan die Moslem kant het ekstremistiese splintergroepe vanweë sekere moreel onaanvaarbare optredes 'n verleentheid vir die Islam as geheel geword.

Die benadering waarvoor gekies word ten opsigte van godsdienstige verskeidenheid is van die uiterste belang (Diener 1997:11). Aan die een kant kan 'n mens opgaan in eksklusivisme. Dit beteken dat alle godsdienste wat anders as jou eie is, in alle opsigte taboe is. Dit vorm in die meeste gevalle die motief vir 'n bepaalde godsdienstige tradisie se missionêre gerigtheid of andersins, weerstand teen uitsluiting van ander godsdienstige tradisies. Vir baie lank was dit die algemene siening vanuit die meeste godsdienstige tradisies.

Die 21ste eeu begin egter met 'n groter openheid. Die opkomende ingesteldheid is dat die ander groot godsdienstige tradisies in hul pluraliteit en verskeidenheid nie noodwendig 'n bedreiging inhou nie. Dit is eerder 'n geleentheid om die realiteit daarvan te erken en die positiewe waarde daarvan te ontgin ter wille van die samelewing waarin hulle funksioneer. (Henrard 2001:52 72) Ons is reeds daarvan bewus dat al die groot godsdienstige bewegings oor lewenswaardes en norme beskik wat tot voordeel van die breër gemeenskap aangewend kan word. Om hierdie gemeenskaplikhede te identifiseer en byeen te bring, is 'n enorme uitdaging. ' $n$ Mens word tog binne 'n bepaalde religieuse tradisie gebore en het daarmee groot geword, hetsy Buddhis, Christen, Hindu, Judaïs, Moslem of een van talle ander. Enersyds is daar bepaalde ooreenkomste wat veral etiese waardes betref, maar andersyds ook verskille. Elke godsdiens het benewens gemeensaamhede met ander unieke oortuigings van sy eie. Selfs $\mathrm{al}$ is die grondliggende teologiese uitgangspunt 'n soteriologiese een, dié van redding, bevryding of transformasie, word dit in die meeste gevalle op totaal verskillende maniere bekom en beleef. Dit geld ook vir etiese aangeleenthede. (Hick \& Askari 1985:6)

\section{Kulturele verskeidenheid}

Nasionaliteit, etnisiteit, demografie en taal vorm die belangrikste grondslag waarvolgens kultuurgroepe ontstaan en voortbestaan. Benewens hierdie verskeidenheid bestaan daar historiese, linguistiese en ander verskille tussen hierdie groepe. Elke groep beskik oor eie kulturele kosbaarhede wat van daardie besondere groep 'n unieke sosiale sisteem maak. Vroeër, toe kommunikasiemiddele nog nie op die gevorderde vlak soos tans was nie, was hierdie groepe meer geïsoleerd en homogeen van aard. Tans is daar meer onderlinge blootstelling ten opsigte van mekaar.

Wat kulturele verskeidenheid betref, bestaan daar 'n ryke verskeidenheid binne elke afsonderlike bevolkingsgroep. Dit kan onder andere op grond van taalverskille benader word. Die Suid-Afrikaanse Grondwet onderskei elf amptelike landstale, te wete Sesotho sa Leboa, Sesotho, Setswana, siSwati, Tshivenda, Xitsonga, Afrikaans, English, isiNdebele, isiXhosa en isiZulu (Die Grondwet van die Republiek van Suid-Afrika: 1996). Die PanSuid-Afrikaanse Taalraad het ten doel om benewens bekende tale ook nog ander soos die Khoi-, Nama- en Santale sowel as gebaretaal, Duits, Grieks, Goedjarati, Hindi, Portugees, Tamil, Teloegoe, Oerdoe, Arabies, Hebreeus, Sanskrit en ander tale wat vir godsdiensdoeleindes gebruik word, te bevorder. Hoewel kulturele eiesoortigheid nie net op taal geskoei is nie, bied die elf amptelike landstale ' $n$ betekenisvolle perspektief op tradisionele kulturele verskeidenheid. Enersyds openbaar mense wat dieselfde taal praat bepaalde kulturele ooreenkomste wat ook op ander vlakke as taal sigbaar word. Voorbeelde hiervan is gedeelde musikale waardes en style en ander uitvoerende kunste soos dramas en opvoerings. Andersyds bestaan daar ook onderlinge verskille binne 'n besondere taalpopulasie. Afrikaanssprekendes op die Kaapse Vlakte leef anders as die Afrikaanssprekende gemeenskap van die ooste van Pretoria en die boerderygemeenskap van Noordwes. Eersgenoemde groep funksioneer grootliks in 'n industriële omgewing met omgangstaal wat daarby pas en laasgenoemde weer in 'n omgewing wat steeds neig tot die tradisionele klasseverskille tussen landheer en werker wat in 'n mate die oorblyfsels uit die apartheidsera weerspieël. Afrikaanssprekendes in die ooste van Pretoria bevind hulle in ' $n$ goot mate in die akademiese- en besigheidsomgewings wat groter professionele vaardighede verg en 'n besondere lewenstyl inhou wat daarby pas.

Almal wat dieselfde taal besig, beskou hulleself ook nie noodwendig as deel van 'n bepaalde kultuurgroep nie. Herkoms speel hierin 'n bepalende rol. In die Engselsprekende gemeenskap is daar byvoorbeeld individue van Skotse afkoms, maar ook van so ver as die Verenigde State van Amerika. Uit die verskillende Swart bevolkingsgoepe is daar individue wat Engels as huistaal besig. Politiek speel ook ' $n$ beduidende rol. Nie alle Afrikaners is gemaklik met die aspirasies van die sogenaamde Boeremag of ander soortgelyke organisasies nie. Nie alle Xhosas is lede van die regerende party, die ANC nie. In die Swart gemeenskappe het die verskeidenheid van stamme sekere kulturele implikasies. Wat by een stam ' $n$ belangrike gebruik is, is nie noodwendig by die ander stam so nie. Mense in die platteland leef anders as mense in die stad met waardes wat ten opsigte van sekere aangeleenthede van mekaar verskil en ten opsigte van ander weer nie verskil nie. Oor die algemeen is plattelanders meer betrokke by ander mense en hul omstandighede as stedelinge. Kulturele afbakening is dus allermins duidelik afgrensbaar. Historiese en demografiese werklikhede speel ook ' $n$ belangrike rol in die ontwikkeling van unieke kulturele gemeenskappe. Dit word sigbaar in die bestaan van eiesoortige kunsvorme, beeldend én uitvoerend. Musiek is 
'n belangrike medium wat op ' $n$ besondere wyse uitdrukking verleen aan kulturele belewenisse en word ook in die skryfkuns en skilderkuns duidelik gereflekteer. Temas wat aan die orde kom, vertel verhale oor die lewens van mense.

Dit is onafwendbaar dat kulturele verskille ook op morele gebied uiteenlopende en selfs botsende waardes sal bewerkstellig. Konsepte soos eiendomsreg, arbeidsetiek, seksualiteit, ouerskap, familie opset, ekonomiese beginsels, eetgewoontes, etiket, ensomeer speel 'n belangrike rol in die uitoefening van norme. Soms bevind deelnemers aan verskillende kulturele groepe hulleself wêrelde uitmekaar ten opsigte van bogenoemde en ander lewenspraktyke. Wanneer sodanige individue of groepe aan mekaar blootgestel word, kan die ervaring van mekaar se gewoontes konflik en selfs vyandigheid laat ontstaan. Dit gebeur veral waar daar eksklusiwiteit, onsensitiwiteit of gebrek aan kennis en insig voorkom.

Die afgelope twee eeue is gekenmerk deur fundamentele veranderings in terme van denke, waardes en sisteme. Modernisme het kennis teen ' $n$ fenomenale pas laat toeneem en nuwe ontwikkelings op tegnologiese gebied het mense se leefwêrelde ingrypend verander. Oor die laaste vyf dekades het die tempo van verandering nog meer versnel. Beter kommunikasiemedia en rekenaartegnologie het 'n onbeperkte bron van inligting tot by die man op straat gebring. ' $n$ Drastiese verskuiwing in terme van die beroepswêreld en die woon- en leefwêrelde van mense het ingetree. Verstedeliking het nie net betrekking op die praktiese lewensomstandighede van mense nie, maar ook op hul denke en maniere van optrede. Aan die een kant was daar 'n prysgawe van ou en getoetste weë en aan die ander kant die wins van nuwe en innoverende denke. Die konsep van tyd het ' $n$ nuwe betekenis gekry. Meer dinge moet in minder tyd gedoen word en daar is nie meer geleentheid vir foute maak nie. Sukses is belangrik. Onderskeid tussen die rolle van mans en vrouens in die samelewing het vervaag aangesien vrouens al hoe meer die professionele beroepswêreld begin betree het. Daar heers 'n sterk kompetisiegees wat die sake- omgewing al hoe meer ongenaakbaar begin maak het. Effektiewe opleiding is van groot belang. Mense se lewenspatroon word tot in die fynste besonderhede gereguleer.

Die nuwe wêreld soos kortliks hierbo beskryf, moes in 'n groot mate afstand doen van tradisionele kulturele inhoude en verhoudings. Plek moes gemaak word vir iets nuuts. Eietydse lewenstyle ontwikkel gou in nuwe vorme en patrone. Kragte soos materiële welvaart en professionele posisionering bring nuwe waardes na vore. Interpersoonlike verhoudings is meer op die korter termyn gerig en dit bring familiebande en verbintenisse soos die huwelik onder druk. Mense beweeg makliker van een werkgewer of selfs beroep en woonplek na die ander. Mense is meer mobiel en aanpasbaar. Dit bring mee dat waardes en norme ook snel aan die kom en gaan is. Die sogenaamde postmoderne ingesteldheid laat mense op 'n nuwe manier oor hulleself en hul werklikheid dink. Die enkeling raak belangriker as die groep en dit het'n gees van individualisme tot gevolg. Markkragte wakker 'n verbruikersingesteldheid aan wat meebring dat druk op hulpbronne toeneem. Baie mense is meer op hul eie voordele ingestel as op dié van die groep en daarom bly waardes soos eerlikheid, opregtheid en lojaliteit dikwels in die slag.

Suid-Afrika word internasionaal beskou as'n ontwikkelende land waar daar 'n oorgang van 'n tipies afhanklike gemeenskap oorbeweeg word na'n selfstandige gemeenskap. Daar bestaan dus 'n ontvanklikheid vir die invloede van groot wêreldmoondhede na gelang ons land tuiskom in die sogenaamde global village. Gevolglik word tradisionele kulturele verhoudings en inhoude opgeoffer ter wille van dit wat nuut en aanloklik is. Mense en instellings word opgeneem in 'n groter geheel waar geykte identiteit dikwels prysgegee word. Verstedeliking, nie net in terme van demografiese verspreiding nie maar ook in terme van denke en ervaring bevestig en bevorder die vorming van 'n nuwe kultuur. (Tomlinson 1999:133)
Hierdie nuwe energie is egter nie net negatief van aard nie. Dit moet eerder beskou word in die lig van die kontemporêre omstandighede en tydsgees en bied nuwe geleenthede in 'n nuwe en opwindende era waar mense anders leef as voorheen. Op kreatiewe maniere word daaraan uitdrukking gegee in die kunste en gewysigde gedragspartone. Wat die een persoon as kulturele fragmentasie en verval beskou, word vir die ander persoon 'n geleentheid vir vernuwing. Wanneer uitgediende kulturele elemente verdwyn en met nuwes vervang word, beweeg mense nader aan mekaar en dien dit tot groter gemeensaamheid en beter onderlinge begrip. 'n Treffende voorbeeld is die oënskynlike vervlakking in kulturele vorme soos tradisionele volksfeeste en die kommer dat mense as gevolg daarvan meer individualisties en onbetrokke sal leef. Nuwe kommunikasmedia soos Facebook en die geweldige groot deelname daaraan bewys dat mense steeds kommunikeer en in nuwe verhoudings betrokke raak. Dit wil voorkom asof mense mekaar makliker as gelykes aanvaar as voorheen. Sterk kompetisie maak nuwe energie los wat op sy beurt kreatiwiteit en ondernemingsgees aanwakker. Dit versnel die lewenspas wat meebring dat mense meer gefokus en doelgerig leef. Die gevolg daarvan is groter effektiwiteit, innovasie en prestasie ook op sosiale gebied.

Op morele gebied skep die komplekse verskeidenheid tot 'n groot mate verwarring ten opsigte van duidelike gedragskodes en -norme. Bo en behalwe die feit dat diverse groepe van mekaar verskil en gevolglik ook hul wyse van gedrag, bring die verskeidenheid ook in 'n sekere mate morele onsekerheid en selfs traak-my-nie-agtigheid na vore. Nuwe kulturele vorme is nie noodwendig sterk moreel-georiënteerd nie en die kragte wat daarin 'n rol speel, is dikwels nie op die welwese van mense gerig nie.

\section{DIE BELANG VAN LEIERSKAP}

Leiers speel altyd 'n deurslaggewende rol ongeag die omgewing waarin hulle funksioneer, of dit nou die politiek, staatkunde, godsdiens, kultuur, onderwys of sakewêreld is.

Polities was Suid-Afrika nog altyd 'n kookpot. Polarisasie was en is nog steeds aan die orde van van die dag. Vanweë verskillende redes word daar maklik nuwe partye gestig, veral in die tyd kort voor 'n verkiesing. Gewoonlik speel die magstryd tussen leiers 'n beduidende rol. Elke party beskik oor 'n bepaalde ideologie wat hulle van ander onderskei. Dié sake kom gewoonlik sterk in hul verkiesingsmanifeste aan die orde en word deur die leiers gepromoveer. Die aansien wat die leiers by die publiek geniet, het 'n beduidende invloed op die sukses wat by die stembus behaal word. Leë verkiesingsbeloftes plaas dikwels 'n vraagteken oor die intensies en integriteit van politieke leiers. Daarteenoor is dit tog belangrik dat diegene met hul doen en late die politieke arena sodanig in te rig dat die invloed wat daarvan uitgaan sal meewerk om aanvaarbare gemeenskapslewe vir almal daar te stel.

In die huidige Suid-Afrika staan regerings- en staatsinstellings wat leierskap betref, onder verdenking. Talle persone in verantwoordelike posisies misbruik hul mag en maak hulleself skuldig aan 'n veelheid vorme van wangedrag. 'n Tragiese voorbeeld hiervan is die skuldigbevinding van ' $\mathrm{n}$ voormalige kommissaris van polisie aan korrupsie. Nepotisme in staatskringe is reeds keer op keer bewys. Hierin speel die onderlinge verskille wat verskeudenheid teweeg bring onder andere 'n beduidende rol. Vir een laag uit die samelewing is dit byvoorbeeld onaanvaarbaar dat 'n hoë amptenaar sy familie op staatskoste met vakansie neem. Vir ander is dit klaarblyklik geen probleem nie.

Demokrasie is inderwaarheid 'n vreemde begrip in die tradisionele Afrika. Leierskap word in die Afrika kultuur volgens stamsenioriteit en bepaalde posisies wat sekere families in die gemeenskap beklee, gereël (Parrinder 1981:67). Tydens 
'n vergadering met tradisionele leiers uit verskillende Swart gemeenskappe op 22 Februarie 2010 het president Jacob Zuma bepaalde ondernemings aangegaan in terme van die invloed van tradisionele kulture op die morele raamwerk asook die rol van tradisionele leiers in die land (Mail \& Guardian). Dit wil dus voorkom asof die huidige staatsbestel met 'n probleem te kampe het wat die posisie van die sogenaamde tradisionele leiers betref. Hoewel hulle ter wille van billikheid iewers in die leierskapskorps geakkommodeer moet word, pas hulle nie in by die moderne konsep van demokraties verkose leiers nie. Verder is dit geen geheim nie dat binne regeringskringe bepaalde persone vanweë hul familiale of tradisionele statuur in sekere posisies aangestel word bó ander wat op grond van meriete veronderstel was om daardie poste te beklee. Enersyds is daar sekerlik begrip vir dié soort van rangordes wat eerbiedig moet word, maar andersyds gebeur dit dat effektiewe leierskap dikwels ingeboet word en dat sekere persone gewoon te ná gekom word. Dit is moeilik om leiers te volg wat nie hul pos waardig is of aan verwagte standaarde voldoen nie.

Suid-Afrika het met die aanvaarding van die huidige grondwet per implikasie van 'n Christelike staat oorgegaan na 'n sekulêre staat. Hoewel dit godsdiensvryheid sonder enige voorskrifte of enige dwang veronderstel, beteken dit nie dat geestelike of godsdienstige leiding nie meer van belang is nie. Mense assosieer op grond van hul geloofsoortuiging met'n bepaalde godsdiens en dit is rigtinggewend vir die wyse waarop hulle inhoud aan hul lewens gee. Die waardes wat sodanige godsdiens voorstaan, is die riglyne waarvolgens hulle hulle gedra. Die belang van leierskap kom daarby in dat godsdienstige waarhede by mense tuisgebring moet word. Leiers moet hul volgelinge deur moeilike tye en probleemsituasies help om die omstandighede sinvol te deurleef. Dit is uit die aard van die komplekse verskeidenheid 'n ewe komplekse aangeleentheid wat sensitiewe leierskap verg. Leierskap behoort nie net van die verskeidenheid bewus te wees nie, maar moet daarin slaag om dit sorgvuldig te bestuur.

Die huidige Suid-Afrikaanse kultuur is meer as net $n$ sameflansing van verskillende kulture. Suid-Afrikaners besig 'n unieke Suid-Afrikaanse lewenstyl wat met wortels in ' $n$ verskeidenheid van kulture uit hierdie bodem gegroei het. Wanneer 'n mens egter vra na leierskap in dié relatief jong kultuur, kry jy nie maklik antwoorde nie. Daar kan dalk eerder gepraat word van 'n spontane ontwikkeling as van doelbewuste leiding deur individue of instansies.

'n Gemeenskap wat gekenmerk word deur verskeidenheid maak dit egter vir leiers uiters moeilik om oor 'n breë front leiding te neem en mense op die pad saam te neem. Waarskynlik moet effektiewe leierskap gesoek word in die samewerking tussen leiers van verskillende groepe wat ook minderheidsgroepe insluit. Op hierdie manier kan die groter saak wat almal raak beter gedien word en groter deelname word bewerkstellig.

\section{IDENTITEIT AS MORELE UITGANGSPUNT}

Niemand bestaan in 'n identiteitlose vakuum nie. Wanneer daar oor iemand se identiteit besin word, gaan dit nie net oor sy individuele psigologiese samestelling, persoonlike vermoëns, kwalifikasies, prestasies, beroep en posisie in die samelewing nie, maar ook oor sy herkoms, demografiese omgewing, sosiale verhoudings, waardes, oortuigings, geloof, toekomsdrome en ideale. Daar kan gevolglik onderskeid gemaak word tussen persoonlike identiteit en groepsidentiteit. Die feit dat'n persoon homself as byvoorbeeld $n$ Blanke manlike Afrikaanssperkende Suid-Afrikaanse Christen beskou, het nie net op sy individuele menslikheid betrekking nie, maar ook op sy sosiale identiteit. Die tipiese Afrika filosofie genaamd $u b u n t u$ beteken juis dat jy is wie jy is op grond van jou deelwees van 'n bepaalde groep.

Om in ' $\mathrm{n}$ diverse samelewing na behore te kan funksioneer en ook ' $n$ bydrae ten opsigte van sinvolle naasbestaan te kan lewer, moet ' $n$ individu sowel as 'n groep sekerheid van die eie identiteit ervaar. Michael Barnes wys daarop dat dit van die grootste belang is om met sekerheid oor jouself in 'n dialogiese verhouding met ander te tree. Dan eers is dit moontlik om ruimte vir ander te maak en ook bereid te wees om van mekaar te leer (Barnes 1989:117).

Die term 'multikulturaliteit' is nie vreemd in die SuidAfrikaanse konteks nie. Dit omvat veel meer as die blote naasbestaan van verskillende groepe of kulture en impliseer die besondere verhoudinge en interaksie van groepe mense en die gevolge daarvan op elke betrokke kultuur sowel as op die geheel. Uit die aard van die saak het die ingewikkelde prosesse wat multikulturalieit teweeg bring ook besondere impak op individue. Wanneer lede van een kultuur blootstelling het aan dié van 'n ander, vind daar'n dinamiese proses van wedersydse beïnvloeding plaas (Kelly 2002:3).

Wanneer individue by mekaar tuiskom in terme van gedeelde godsdienstige oortuigings en tradisionele waardes en gewoontes, ontwikkel daar gedragskodes wat op beginsels geskoei is. Deur 'n proses van formele en informele kontrole word dit voortgesit en uitgebou. Uiteindelik bied dié stel morele kodes sekuriteit en gee dit verder uitdrukking aan 'n gedeelde identiteit. Inisiasie prosedures in Swart gemeenskappe is 'n voorbeeld hiervan sowel as die siening van die huwelik en die rol van die vrou in ander gemeenskappe. Verskillende groepe het ook vooren afkeure, taboes en toelaatbare gedrag waar dit kom by ' $n$ sensitiewe aangeleentheid soos seksualiteit. Sekere groepe in die Moslem gemeenskap laat byvoorbeeld nie toe dat 'n man en sy vriendin voor die huwelik saam uitgaan nie. By ander word saamwoon buite die huwelik ' $\mathrm{n}$ algemene aanvaarde praktyk. Die kosher eetgewoontes by Judaïste en halaal eetgewoontes by Moslems is praktiese voorbeelde van morele oriëntasie by hierdie twee geloofsgroepe. Die besondere groepe konformeer ten opsigte van hierdie morele gedragskodes en dit versterk en gee uitdrukking aan hul unieke identiteit. (Holley, Kromkowski \& Magliola 2004:109)

Namate die wêreld aan die verander is, is die belewenis van mense se identiteit ook aan die verander. Hierin het tendense soos post-moderne denke en verstedeliking 'n beduidende rol. Dit is veral die jonger mense wat hulleself gemaklik en tuis voel in die sogenaamde global village waar hulle deelneem aan die nuwe kultuur, genaamd urban culture. Beter kommunikasie middele, inligtingsbronne en vervoerstelsels maak dit moontlik om wêrelde wat eers ver uitmekaar gelê het, makliker te verbind. Eertydse vaste kodes wat identiteit betref, vervaag al hoe meer om plek te maak vir nuwe vorme daarvan.

In Suid-Afrika waar die nuwe politieke bestel die inwoners van die land op 'n meer gelyke speelveld gebring het, is daar groter blootstelling aan tradisioneel diverse groepe. Nuwe gedeelde belange soos aangetref in die arbeidsmark, op die sportveld, in die akademiese wêreld, ensomeer is geneig om ou grense te oorskry en nuwe inhoud te genereer. Mense vind mekaar op nuwe en verrassende terreine en 'n nuwe gedeelde identiteit ontwikkel en groei.

\section{DINAMIKA IN VERSKEIDENHEID}

Die wyse waarop verskeidenheid bestuur word, is van die allergrootste noodsaak wanneer dit by die soeke na 'n sinvolle en aanvaarbare morele lewe vir almal kom. Daar is myns insiens drie uitgangspunte ter sake.

Eerstens is dit belangrik dat samelewings verskeidenheid sal erken. Dit gebeur nie vanself nie en vra 'n besondere ingesteldheid van openheid. Sonder om van meet af bedreigd te wees of te voel, moet individue en groepe kennis neem dat daar naas hulleself ook persone en groepe is wat 'anders' is wat sekere aspekte betref. Dié andersheid kan voor die hand liggend wees soos wanneer daar groepe van verskeidenheid van kleur in een samelewing woon en werk. Dit kan egter ook 
baie meer subtiel wees soos wanneer families bepaalde bande het en unieke gebruike handhaaf waar geen ander persoon in kan deel of by kan inpas nie (Krige 1977:120). Alvorens die werklikheidsverskynsel van verskeidenheid nie vierkant in die oë gekyk word nie en nie na behore in samelewings in ag geneem word nie, sal daar eenvoudig nie in geslaag kan word om die konflikte wat mag ontstaan, te hanteer nie.

Tweedens moet die mening dat verskeidenheid per se net negatief is, afgewys word. Indien dit as 'n vyand beskou word, is die risiko soveel hoër dat dit geminag of van minder belang geag word. Dan is die moontlikhede soveel groter dat meerderheidsgroepe oor minderhede kan heers en dat betekenisvolle rolspelers gemarginaliseer kan word. Die handhawing en uitbouing van kleiner eenhede bring mee dat identiteitsvorming makliker plaasvind en dat ruimtes geskep word waarin mense veilig voel en beter funksioneer. 'Variety' is immers 'the spice of life'.

Derdens is 'n doelbewuste bestuursprogram noodsaaklik. Verskil van menings en belange het ongelukkig dikwels verwydering tot gevolg wat tot spanning en konflik kan lei en op sy beurt weer tot aktivisme en geweld. Dit is destruktief. Indien verskille reg bestuur word, het dit egter nie net harmonie en samewerking tot gevolg nie, maar kan daar baie positiewe en opbouende waarde uit kom. Met swak bestuur het die grondhervormingsprogram in Suid-Afrika byvoorbeeld die potensiaal tot rampspoedige gevolge soos daar reeds in die buurland, Zimbabwe genoegsame bewyse voor bestaan. Daar is tog reeds enkele voorbeelde van hervormingsprosesse wat met die regte bestuurskundigheid hanteer word en uiters suksesvol is. Wat egter deurslaggewend is in enige bestuursprogram, is die wyse van bestuur en in die besonder die bestuurstyle van leiers en betrokkenes. Dit vereis bepaalde vaardighede en integriteit (April \& Shockley 2007:15).

Die omgewings waar mense hulle bevind, het ' $\mathrm{n}$ ingrypende invloed op die wyse waarop hulle leef. 'n Voor die hand liggende voorbeeld hiervan is die uiteenlopendheid tussen die stad en platteland in Suid-Afrika. Sonder om te veralgemeen is daar by plattelanders ' $n$ merkbare groter rustigheid en lewendiger gemeenskapsbetrokkenheid as by stedelinge. Die pas in die stad is snel, verhoudings vlakker en van korter duur en die belewenisse meer momenteel van aard. Tyd en ruimte is beperk.

Daar kan ook 'n onderskeid gemaak word tussen moderne en pre-moderne lewenstyle. Hier gaan dit eerder oor die tydsgees as oor die omgewing. Tegnologiese ontwikkeling en 'n groter klem op wedywering het bepaalde invloede op die wyse waarop mense leef. Die neiging bestaan dat mense al hoe meer individualisties dink en optree. Norme en gewoontes is nie meer vas en rigied nie. Daar bestaan baie keuses en dis jou reg om jou eie mening te huldig en jou eie keuses uit te oefen. Verder het die verbruikersgees sy voet behoorlik in die deur gedwing. Dit het 'n lewenstyl geword om gereeld uit te gaan, by kuierplekke te verkeer, maaltye saam met kollegas en vriende in straatkafees en restaurante te geniet en naweke uit die stad te beweeg. In die beroepswêreld is die suksesleer belangrik en alle energie word ingespan vir eie voordeel.

Hierdie leefwyses maak 'n nuwe kultuurmoontlikheid oop. Dit staan los van tradisionele kulture, etnisiteit, geslagtelikheid en herkoms. Dié nuwe leefstyl is eie aan die jong en opkomende geslag en is 'n dinamiese groeiproses wat nuwe horisonne open. Geleenthede soos internasionale sportbyeenkomste en die gedeelde belangstelling wat dit wek, funksioneer as samebindende faktore wat nuwe kulture tot gevolg het. Dieselfde geld vir sport deelname en ontspannings-ekskursies wat die plek inneem van tradisionele kulturele aktiwiteite. Die uitgebreide film industrie is veel meer as 'n vermaaklikheidsmedium. Dit kan beskou word as hedendaagse kuns wat samelewingspatrone vertoon en interpreteer. Deur daaraan blootgestel te word, word die samelewing beïnvloed wat weer op sy beurt daarop reageer. Argitektuur en die uitleg van woon- en werkplekke dra by tot nuwe maniere van leef. Kompleks-behuising dra nie werklik by tot groter gemeenskapsbetrokkenheid nie, maar eerder tot bekostigbaarheid, woongerief en minder verantwoordelikhede. Bejaardes wat in aftree-oorde woon, is nie meer die verantwoordelikheid van die breëre gemeenskap nie, maar bly langer onafhanklik en vrywaar daardeur hul families in 'n groot mate van die praktiese verpligtinge. Hierdie stelling geld ook vir gespesialiseerde inrigtingsorg.

Bogenoemde voorbeelde dui op'n groter fokus op individualisme. Dit vra op sy beurt weer na groter finansiële vermoëns wat 'n gees van materialisme aanwakker. 'n Oordrewe kompetisie gees dra verder daartoe by. Markkragte raak dus al hoe belangriker (Tomlinson 1999:81).

Al hierdie lewenswerklikhede vereis dat mense op besondere maniere daarop sal reageer en algaande vind dit neerslag in die vorming van wat genoem kan word: nuwe kulture, soos die sogenaamde urban culture of global culture (Schlereth 1977:12). Dit is kultuur wat naas ander identifiseerbare kulture bestaan ten spyte en te midde van geykte kulturele grense.

\section{DIE ONTWIKKELING VAN 'N NUWE MORELE BEWUSSYN}

Die historiese verloop in Suid-Afrika sedert die tyd voor kolonialisasie was gekenmerk deur segregasie. Inheemse Afrika bevolkingsgroepe het outonoom naas mekaar gefunksioneer en dikwels het botsende belange en insidente op konflik en selfs bloedvergieting uitgeloop. Hoewel koloniste van Europese afkoms wat godsdiens en kultuur betref, veel in gemeen gehad het, het hulle vir lank hul afsonderlike identiteite gehandhaaf. Hoewel die sogenaamde beleid van afsonderlike ontwikkeling van die apartheidsregering op rasseverskille ingestem was, is daar ook voorsiening gemaak vir die handhawing van kleiner groepe en kulture se unieke eiesoortigheid. Die voorkoms van verskeidenheid kon nog nooit ontken word nie, want dit is 'n gegewe werklikheid. Tog is dit in 'n land soos Suid-Afrika meer merkbaar vanweë die besondere kompleksiteit van die bevolkingsamestelling, verskillende kulture, subkulture en godsdienste wat hier voorkom. Demokratisering van die politieke- sake- en die gemeenskapslewe het mense uiteindelik baie nader aan mekaar gebring. Onderlinge skakeling is deurlopend en meer intiem deurdat interaksie tussen mense uit wyd uiteenlopende leefwêrelde en agtergronde daagliks plaasvind. In samehang met die erkenning van verskeidenheid soos hierbo bespreek, is daar 'n oplewing in die herwaardering van mense, hul waarde en kwaliteite. Dit gebeur veral wanneer mense uit hulle gemaksones bewweg en daar 'n ontdekking van die ander plaasvind. Mense kom agter dat ander se belange, behoeftes, probleme en drome nie veel van hul eie verskil nie al vind mens jouself tuis in 'n totaal andersoortige milieu as hulle. Hierdie is ' $n$ baie belangrike insig waartoe 'n groot deel van die huidige Suid-Afrikaanse bevolking oor die afgelope paar jaar gekom het. Die gevolg daarvan is 'n gesindheidsverandering wat meebring dat mense nie meer soveel op hulleself en hul eie belange gerig is nie. Ongeag onderlinge verskille word ander al hoe meer as gelykes beskou en waardeer. Dit hou groot wins vir 'n positiewe morele oriëntasie in.

Hoë misdaadsyfers en grootskaalse morele vervlakking in die Suid-Afrikaanse samelewing is aanduiders wat nie oor die hoof gesien kan word nie. Hopelik fokus dit nie net die aandag op die veelvoudige sosiale en maatskaplike probleme nie, maar roep dit hard genoeg om 'n daadwerklike poging tot morele herstel. Dit is veral die omvattende verskeidenheid in die land wat 'n uitdagende en opwindende omgewing skep waar nuwe verhoudings gebou moet word. Hoewel die beroepswêreld uiters kompleks van aard is, veral met regstellende aksie wat soms ongenaakbaar toegepas word, is dit tog 'n unieke tyd en milieu wat besondere eise aan mense se skeppende vermoëns stel. Almal in die werksplek se arbeidsetiek is immers nie dieselfde 
nie. Wanneer mense vanuit verskillende kulturele agtergronde deur die werklikhede van hul omgewing genoodsaak word om gemeenskaplike doelwitte na te streef, skep dit geleenthede vir interaksie. Dit verbreed horisonne en akkommodeer mense uit verskillende omgewings. Noodgedwonge sal daar blootstelling aan mekaar se gebruike, gewoontes en gelowe wees wat ook waardes en norme insluit. Dit mag konflik, verwydering of selfs gewelddadigheid en misdaad tot gevolg hê. Maar dit kan ook verrykend inwerk om gemeenskaplike drome te deel en doelwitte na te streef.

\section{GELEENTHEID VIR DIE KERK}

Die Kerk leef en werk in die Suid-Afrikaanse omgewing te midde van al die werklikhede soos kortliks hierbo omskryf. Wanneer daar bevind word dat die land tans 'n moraliteitskrisis beleef, kom die invloed wat die kerk uitoefen, of veronderstel is om uit te oefen, in die kollig. Hoewel morele leiding nie die primêre taak van die kerk is nie, is dit ook nie uitgesluit nie. Godsdiens het immers sterk morele implikasies. Die veronderstelling is egter nie dat die kerk op dié vlak misluk nie. Tog kan daar gevra word na 'n meer effektiewe bydrae wat die kerk ter wille van 'n gelukkige samelewing kan lewer. Dié argument bevestig die oortuiging van die Katolieke teoloog, Hans Küng, dat die kerk 'n dinamiese organisme is wat deurlopend aan die verander is ten einde vormend op die omgewing waarvan hy deel is, kreatief en vernuwend in te speel (Küng 1981:4).

Namate die sekularisasieproses al hoe meer toegeneem het, het die statuur wat die kerk tradisioneel beklee het, begin kwyn. In al hoe mindere mate word daar gevra na die kerk se standpunt oor morele aangeleenthede en wanneer die kerk van sy kant insette probeer maak deur voorstelle of besware, word daar nie met dieselfde aandag en sensitiwiteit as in die verlede na geluister nie. 'n Voorbeeld hiervan is die besware van die kerk ten opsigte van aborsie op aanvraag. Hierdie tendens is ' $n$ werklikheid wat die kerk in sy strategiese beplanning al hoe meer sal moet verdiskonteer.

Die Kerk bly God se verteenwoordigers op die aarde. As navolgers van Jesus Christus heers die kerk saam met Hom oor die bose en alles wat volgens Christelike beginsels verkeerd of onaanvaarbaar is. Om te heers beteken egter nie net om te wees nie, maar ook te doen. Die kerk kan min uit sy eie doen, maar saam met Christus doen die kerk mee aan baie dinge. Dus moet die kerk met nuwe ywer en entoesiasme erns maak met sy Godgegewe roeping deur al hoe meer te wees wat hy inderwaarheid reeds is. Dan kan die taak van die kerk eers effektief tot sy reg kom. Hierdie is die noodsaaklike vertrekpunt van die kerk se werk wat vanuit die Bybel as God se Woord begrond word. Verder moet die kerk relevant wees vir sy tyd en omstandigheid en deeglik rekening hou met die nuwe speelveld waarop hy hom in Suid-Afrika bevind.

Hoewel die Kerk homself op bekende bane tuis voel en hy in die verlede aan die hand van bepaalde werkswyses sukses behaal het waar dit by sy taak van morele leiding kom, sal hy wat die toekoms betref, sekere paradigmaskuiwe moet maak. Hy sal byvoorbeeld minder veroordelend en meer akkommoderend te werk moet gaan. Hy sal minder na binne, maar meer na buite gerig moet wees. Hy sal oor baie dinge nuut en vars moet dink. Hy sal ook moet toelaat dat nuwe teologiese insigte sy denke verlig al druis dit in teen ou opvattings. Ook wat sy modus operandi betref, sal hy moet improviseer. Gemeentelike bedieningstyle sal moet aanpas by die omstandighede van die tyd. Om dieselfde resultate as in die verlede te behaal, sal sy manier van dink en doen vars en nuut moet word. Die kerk sal nuwe brue op innoverende wyses moet bou. Nuwe geleenthede om op morele gebied 'n bydrae te maak, moet nie net ontdek word nie, maar ook op 'n kreatiewe wyse geskep word.

Die kerk mag egter nooit sy missio Dei vergeet of versaak nie. Morele genesing van die land moet altyd die uitvloeisel van sy groter opdrag, naamlik die verkondiging van die evangelie in al sy verbande wees (Bosch 1996:519).

Die roeping van die kerk kan breedweg tweeledig beskou word.

\section{Die Kerk se gerigtheid na binne}

Die beste vertrekpunt vanwaar die kerk sy interne morele aksie kan benader, is dié van bewoënheid. Dit beteken dat die kerk sy eie skuld ten opsigte van die moraliteitskrisis in die land sal erken. Alle kerke het in mindere of meerdere mate deel aan dié ongewenste toestand vanweë 'n verskeidenheid redes. As voorbeeld hiervan dien die sanksionering en selfs Bybelse regverdiging van die apartheidsbeleid deur die Afrikaanse en sommige ander kerke. Daar is ook talle voorbeelde van versuim op verskillende terreine. Voorbeelde daarvan is die versuim om te waarsku teen ' $n$ materialistiese lewenstyl en uitbuiting van werkers en gevolge van die enorme afstand tussen ryk en arm, die oorsake van HIV en die verheerliking van menslike rolmodelle. Op daardie pad moet teruggegaan word en regstellings gedoen word waar dit nog nie gedoen is nie.

Die kerk moet die immorele gedrag van sy eie lidmate identifiseer en sterk veroordeel. Dit gaan gepaard met 'n pastorale plig om nie te skroom om lidmate op te roep tot bekering van vergryp wat in die kerk 'sonde' genoem word nie. Alle moreel onaanvaarbare optredes is natuurlik nie sonde nie. Tog moet daar morele dissipline geld selfs ook ten opsigte van die nie-so-ernstige vergrype. Hoewel dit vra vir eerlikheid en beslistheid, moet dit ook met die nodige sensitiwiteit gepaard gaan. Korrupsie deur kerkmense en gesinsgeweld, hoe subtiel dit ookal in gelowige huise mag voorkom, moet uitgewan word. Lidmate moet begelei word om te verstaan dat hulle persoonlik én kollektief aandadig is aan sosiale wanorde en dat hulle nie net die verantwoordelikhede daarvoor moet aanvaar nie, maar ook daarvan afstand moet doen.

Aangesien morele waardes veral tydens kinderjare gevestig word, moet kategetiese onderrig en opvoedingsprogramme aan kinders en ouers daarin slaag om Bybelse norme in die lewens van kinders te vestig. Toerustingsmateriaal moet die ontwikkeling- en bevatlikheidsvlakke van die onderskeie ouderdomsgroepe deeglik in ag neem. Daar moet ook begrip wees vir die besondere omstandighede van kinders. Dit is ongelukkig 'n werklikheid dat baie kinders in gebroke of saamgestelde huishoudings grootword en gevolglik 'n groot mate van ontwrigting beleef. Waar daar nie begrip is vir dié besondere lewensomstandighede nie, sal die invloed van die kerk nouliks tot sy reg kan kom. Dit is verder noodsaaklik om te verstaan dat die kerk met sy kategetiese materiaal en wyse van aanbieding in kompetisie met die vermaaklikheidsmedia verkeer. Daarom moet dit van hoogstaande en toepaslike aard wees en werklik in die leefwêreld van moderne kinders kan inspeel. Bybelse literatuur verleen vanweë die besondere aard daarvan hom uitstekend daartoe om narratief en verbeeldingryk Bybelse waardes te kommunikeer en vas te lê. Die kerk sal ook'n manier moet vind om ouers te inspireer om kinders by kategese in te laat skakel en self daarby betrokke te wees. Die gesinsjaar wat die NG Kerk gedurende 1994 geïmplementeer het, was 'n geslaagde poging om kinders en ouers in gesinsverband geestelik en moreel te begelei. Daar is moontlik ook ander voorbeelde. In die jongste tyd het daar nuwe innoverende jeugen kategeseprogramme die lig gesien wat deur gemeentes met groot vrug gebruik word. Geestelike musiek wat op kinders en tieners gerig is, spreek hulle beter as baie ander pogings aan om hulle geestelik te laat groei en waardes tuis te bring.

'n Verdere vaardigheid wat help om mense moreel beter te laat funksioneer, is die aksie van dienslewering. Benewens die feit dat dit in die meeste gevalle hulpverlening aan ander is, bewerkstellig dit 'n gees van omgee en om goed te doen. Vir die persoon self hou dit groot voordeel in wat betref sy eie morele mondering. 
In 'n omgewing waar lidmate blootgestel word aan diverse invloede ook op morele vlak, het die kerk die geleentheid om hulle toe te rus om nie net as Christene te oorleef nie, maar ook selfstandig, verantwoordelike en eties korrekte keuses te maak en invloed uit te oefen. Hulle moet nie napraters van 'n kerklike dogma of argument wees nie, maar geestelik-moreel volwasse genoeg om self goed verantwoorde keuses uit te oefen bydraes te lewer. Hulle moet, sonder om tradisionele waardes summier oorboord te gooi, daarin kan slaag om vanuit hul leefwêreld by nuwe en behoudende oplossings vir morele kwessies uit te kom wat Bybels verantwoordbaar en moreel bevorderlik is. Tans is die netelige kwessie van saamwoon buite die huwelik (en seksuele verkeer buite die huwelik) nie net op die kerk se agenda nie, maar ook 'n gewilde onderwerp in gesprekke. Die kerk doen ook moeite om nie ondeurdagte of fundamentalistiese antwoorde te gee oor vrae rondom homoseksualiteit nie.

Die kerk se Godsbegrip, Skrifbeskouing, kerkbegrip, wêreldbeeld en lewensbeskouing moet weldeurdag en gefundeerd wees en die lidmate van die kerk moet dit verstaan. Daarmee saam moet die kerk sy lidmate deur die erediens, Bybelstudies, gespreksgeleenthede en ander toerustingsprogramme bemagtig om vanuit ' $n$ etiek van geloof en verantwoordelikheid voluit aan die lewe deel te neem. Dieerediens wat na bykans almal se mening die hartklop van die gemeentelike bediening is, moet sodanig ingerig word om die lidmate te begelei in ' $n$ ware ontmoeting met God. Wanneer alle geloofsinhoude in die erediens behoorlik tot hul reg kom, sal die morele verantwoordelikhede wat daaruit voortspruit, ook tot hul reg kom. Die reddende genade van God sluit nie menslike verantwoordelikhede uit nie, maar bevestig dit juis.

Die kerk moet wees wat hy reeds is: kerk, en ook sodanig optree. Konkreet beteken dit byvoorbeeld dat die kerk nie ' $n$ sakeonderneming is wat op besigheidsbeginsels bedryf word nie, al moet die kerk fondse hanteer. Die barmhartigheidsdiens van die kerk staan in diens van die Evangelie en word nie uit humanistiese oorwegings gedoen nie. Daarom voed die kerk honger mense al is dit nie sy primêre taak nie. Kerklike geskille en probleme word op ' $n$ kerklike manier hanteer, anders as in die sekulêre wêreld, omdat die kerk ' $n$ eiesoortige instelling is.

In aansluiting by bogenoemde moet die kerk die lidmate begelei om alle mense, ongeag verskeidenheid ten opsigte van religie en kultuur of watter ander verskeidenheid mag voorkom te respekteer as gelykes. Dit is immers 'n praktiese Christelike deug wat ononderhandelbaar is en van alle Christene vereis word. In Suid-Afrika is dit van die allergrootste noodsaak. Eksklusiwiteit pas nie in die Christelike geloofstradisie nie. Wanneer die kerk seker is van sy eie identiteit in terme van teologiese en sosiale verbande, word dit moontlik om homself nie net te handhaaf nie, maar ook deur goeie betrekkinge met ander in ' $n$ diverse omgewing uit te leef.

\section{Die Kerk se gerigtheid na buite}

Aanvaarbare gerigtheid na buite vereis ook ongekwalifiseerde bewoënheid van die kerk. Dit is eie aan die kerk om hand in eie boesem te steek wanneer morele verval ter sprake is. Soms is die prys groot soos in die geval van die Nederduitse Gereformeerde Kerk wat sy aandeel aan apartheid by verskeie geleenthede teenoor verskeie persone en instansies bely het. Dit het ' $n$ dramatiese kerkskeuring tot gevolg gehad. Maar dié kerk het daarmee sy integriteit in 'n groot mate herwin. Die kerk moenie net teenoor God nie, maar ook teenoor die wêreld bely.

Daar is reeds aangetoon dat die kerk nie meer sy bevoorregte posisie in die samelewing beklee nie. Om steeds ' $n$ invloed te kan uitoefen, is een van die innoverende tegnieke om jou stem by dié van ander te voeg. Daarom sluit die kerk vennootskappe in ekumeniese en ander verbande. By geleentheid is dit ter wille van sekere sake selfs nodig om in samewerking met instansies te tree met wie daar op ander terreine hemelsbreed verskil word.
Daar is reeds op gewys dat daar veral op morele gebied talle raakvlakke met ander godsdienste bestaan.

Die profetiese roeping van die kerk sluit ook samewerking en ondersteuning van instansies soos die regering en nieregeringsorganisasies in. Waar daar positiewe werk gedoen en resultate behaal word, behoort die kerk die nodige erkenning te gee en dit verder aan te moedig.

Met die rykdom van hulpmiddels waaroor die kerk beskik, moet hy al hoe meer die oorsake van morele agteruitgang aanspreek. Dit sluit verskynsels soos drank- en dwelmmisbruik, verskillende vorme van geweld en misdaad, werkloosheid, armoede en epidemies in. Die kerk sal moet kom met prakties werkbare modelle en programme waarvolgens daar doelgerig gewerk kan word om dié komplekse problematiek aan te spreek. Om dit nog meer effektief te maak en ook relevant, moet dit in samewerking met ander rolspelers gedoen word. Dit sal die geloofwaardigheid van die kerk in die oë van die groter bevolking versterk.

Die kerk mag hom nooit isoleer nie. Daarom moet sy lidmate steeds aan die politiek, kultuur, sport en openbare debat op 'n Christelike manier deelneem en op daardie en ander terreine positief inspeel in die morele genesing van die land. Daar is al by talle geleenthede gewys op die kerk se grootste bate naas die geloof in God, naamlik die hoë kwaliteit mensemateriaal waaruit sy lidmate bestaan. Hul deelname en getuienis bly tog maar die beste manier waarop die kerk in die wêreld 'n verskil kan maak. Dit is die manier hoe God dit doen.

'n Term wat al hoe meer in kerklike gesprekke en by vergaderings gehoor word, is die 'gestuurdheid' van die kerk. Daar word ook veel gewag gemaak van die uitdaging wat die kerk in die oë staar om 'oor grense' te beweeg. Hierdie positiewe energie kom tuis in bedieningsmodelle en kerklike projekte wat daarop gerig word om gemeentes te organiseer en toe te rus sodat lidmate doelgerig en met entoesiasme en effektiwiteit missionêr aktief kan wees. Met' $n$ holistiese benadering word daar nie net gefokus op die kerstening van mense nie, maar ook op die invloed wat die kerk ten opsigte van moraliteit kan uitoefen. Waar hierdie geleentheid met die nodige sensitiwiteit en integriteit aangegryp word, behoort die kerk ' $n$ enorme verskil in die samelewing te kan maak.

\section{Verskillende bedieningsmodelle}

Kerklike en gemeentelike bedieningsmodelle word oor die algemeen op Bybelse en veral Nuwe Testamentiese metafore vir die kerk gebou. Daar word gedink aan die uitverkore volk, koninklike priesterdom, nasie wat vir God afgesonder is, eiendomsvolk van God, volk wat die verlossingsdade moet verkondig van Hom wat julle uit die duisternis geroep het na sy wonderbare lig van 1 Petrus 2:9. Die kerk word ook die sout vir die aarde (Matt 5:13), brief van Christus (2 Kor 3:3), nuwe suurdeeg (1 Kor 5:6), wingerdlote (Joh 15:5), gebou van God (1 Kor 3:9), uitverkore vrou (2 Joh 1:1), bruid van Christus (2 Kor 1:11), draers van wit klere (Op 7:9-11), medeburgers van die gelowiges en lede van die huisgesin van God (Ef 2:19), liggaam van Christus (Rom 5-8). Benewens genoemdes is daar nog baie ander beelde (Minear 1960:28-66, 173-180). Gemeentes en kerke gebruik graag die betekenis van' $n$ bepaalde metafoor as kernbeginsel waarop hul bedieningsmodel gebou word. Hiermee word uitdrukking gegee aan die unieke karakter van so'n gemeente, asook die mees sentrale bedieningsarea(s).

Daar is ook buite-bybelse bedieningsmodelle wat neig om eerder by die sekulêre omgewing of ander werklikhede kers op te steek. In die meeste gevalle word dit strategies ontwerp ten einde die bediening van' $n$ kerk of gemeente op die mees effektiewe wyse in terme van die besondere doelwitte en praktiese omstandighede te reël. Daar vind gewoonlik' $n$ klemverskuiwing vanaf Bybelsedogmatiese beginsels na prakties-kontemporêre lewenskwessies plaas. 
Die verskeidenheid in bedieningsmodelle onderskryf die verskeidenheid in wêreld en kerk. Ons leef nou eenmaal nie in 'n homogene of enkelvoudige omgewing nie. Om relevant te kan wees, moet die kerk daarmee in pas wees. Dit wil nie die eenheid ophef nie, maar maak erns met verskeidenheid te midde van eenheid.

Saam met ander rolspelers soos die staat, nie-regeringsorganisasies, die akademiese omgewing, onderwysinstansies, die private sektor ensomeer sal die kerk homself moet oriënteer as 'n effektiewe en onontbeerlike stimulus ten opsigte van morele genesing van Suid-Afrika.

\section{LITERATUURVERWYSINGS}

April, K. \& Shockley, M., (eds.), 2007, Diversity. New Realities in a Changing World [Diversiteit. Nuwe werklikhede in ' $\mathrm{n}$ veranderde wêreld], Palgrave Macmillan, Hampshire \& New York.

Barnes, M., 1989, Christian Identity and Religious Pluralism [Christelike identiteit en religieuse pluralisme], Abington, Nashville.

Bosch, D.J., 1996, Transforming Mission. Paradigm Shifts in Theology of Mission [Transformerende sending. Paradigma skuiwe in die teologiese sending], Orbis Books, New York.

De Villiers, D.E., 1999, ‘Die NG Kerk en die oorgang na 'n nuwe Suid-Afrika', Skrif en Kerk 20(1), 15-38.

Diener, P., 1997, Religion \& Morality. An Introduction ['n Inleiding na godsdiens en moraliteit], Westminster John Knox Press, Louisville.

Henrard, K., 2001, 'The accommodation of religious diversity in South Africa against the background of the centrality of the equality principle in the new constitutional dispensation', Journal of African Law, 45(1), 51-72.
Hick, J. \& Askari, H., (eds.), 1985, The Experience of Religious Diversity [Die ondervinding van godsdienstige diversiteit], Gower, Aldershot.

Holley, H., Kromkowski, J. \& Magliola, R., 2004, Religion, Morality and Communication between Peoples : Religion in Public Life. Volume $i$ [Godsdiens, moraliteit en kommunikasie tussen mense: Godsdiens in die openbare lewe. Deel 1], The Council for Research and Philosophy Library of Congress Cataloging-in-Publication, USA.

Kelly, P., (ed.), 2002, Multiculturalism Reconsidered [Multi-kulturialisme heroorweeg], Polity Press, Cambridge.

Krige, E.J., 1977, The Social System of the Zulu [Die sosiale sisteem van die Zoeloel, Shuter \& Shooter, Pietermaritzburg.

Küng, H., 1981, The Church [Die kerk], Search Press, London.

Mail \& Guardian, 2010, Zuma pushes for debate on national code, viewed 23 February 2010, from http://www.mg.co.za/ article/2010-02-23-zuma-pushes-for-debate-on-nationalmoral-code

Morgan, P. \& Lawton, C., 1996, Ethical Issues in Six Religious Traditions [Etiese strydpunte in ses godsdienstige tradisies], Edinburgh University Press, Edinburgh.

Parrinder, E.G., 1981, African Traditional Religion [Tradisionele Afrika godsdiens], London, Sheldon Press.

Rauch, J., 2005, Crime Prevention and Morality. The campaign for moral regeneration in South Africa. ISS Monograph Series. No 14 Institute for Security Studies, Pretoria.

Schlereth, T.J., 1977, The Cosmopolitan Ideal in Enlightenment Thought [Die kosmopolitiese ideaal in die verligte denke], University of Notre Dame Press. Notre Dame.

Tomlinson, J., 1999, Globalisation and Culture [Globalisasie en kultuur], University of Chicago Press, Chicago. 